University of Wollongong

Research Online

Faculty of Social Sciences - Papers (Archive) Faculty of Arts, Social Sciences \& Humanities

2014

Making country good: stewardship and environmental change in central Australian pastoral culture

Nicholas Gill

University of Wollongong, ngill@uow.edu.au

Follow this and additional works at: https://ro.uow.edu.au/sspapers

Part of the Education Commons, and the Social and Behavioral Sciences Commons

Research Online is the open access institutional repository for the University of Wollongong. For further information contact the UOW Library: research-pubs@uow.edu.au 


\title{
Making country good: stewardship and environmental change in central Australian pastoral culture
}

\begin{abstract}
Rural stewardship has been a focus of much natural resource management policy in Australia and elsewhere. Despite landowners professing stewardship, some researchers have cast doubt on the utility of the concept due to its vagueness and difficulties of associating attitudes with behaviour. In contrast I argue that stewardship should remain an important concept for understanding rural cultures, landholder practices and the politics of land. Stewardship, however, needs to be understood as emergent, as a 'dwelt achievement', as having temporal depth and as being part of the production of socio-natures. Moreover, as a key vernacular practice, its capacities and vulnerabilities require critical interpretation. I pursue these issues through an analysis of 20th-century pastoral stewardship in central Australian rangelands where land-use ideals have long been tested by aridity and low productivity. Arid zone pastoralism has also been subject to on-going critique and re-evaluation as ecological and other values challenge pastoral practice and the very presence of pastoralism. Pastoralists have responded with varying articulations of stewardship. These share consistent foundations even as their form changes. I use Anderson's idea (1997) of 'critical domestication' to underpin this analysis and show that pastoral stewardship has been, and continues to be, characterised by interpolations of order and chaos in nature and of continuity and discontinuity. With its focus on humanist ontologies of human distinction from the natural world rather than specific land-use ideals, critical domestication provides a framework for critically interpreting these interpolations in landscapes where ideals such as cultivation and closer settlement have not been achieved. Allying this framework with recent perspectives on the agency and materiality of nature, I also show that stewardship is not solely a human achievement, but is co-produced by environmental variability, plants and domestic and feral animals such as cattle and rabbits.
\end{abstract}

\section{Keywords}

era2015, change, good, stewardship, central, environmental, country, culture, pastoral, making, australian

\section{Disciplines}

Education | Social and Behavioral Sciences

\section{Publication Details}

Gill, N. (2014). Making country good: stewardship and environmental change in central Australian pastoral culture. Transactions of the Institute of British Geographers, 39 (2), 265-277. 
Making Country Good: Stewardship and Environmental Change in Central Australian Pastoral Culture

\author{
Nicholas Gill \\ Australian Centre for Cultural Environmental Research \\ School of Earth and Environmental Science \\ University of Wollongong \\ NSW 2522
}

$\mathrm{Ph}+61242214165$

Fax +61 242214250

ngill@uow.edu.au 
Rural stewardship has been a focus of much natural resource management policy in Australia and elsewhere. Despite landowners professing stewardship, some researchers have cast doubt on the utility of the concept due to its vagueness and difficulties of associating attitudes with behaviour. In contrast I argue that stewardship should remain an important concept for understanding rural cultures, landholder practices, and the politics of land. Stewardship, however, needs to be understood as emergent, as a 'dwelt achievement', as having temporal depth, and as being part of the production of socio-natures. Moreover, as a key vernacular practice, its capacities and vulnerabilities require critical interpretation. I pursue these issues through an analysis of twentieth century pastoral stewardship in Central Australian rangelands where land use ideals have long been tested by aridity and low productivity. Arid zone pastoralism has also been subject to ongoing critique and re-evaluation as ecological and other values challenge pastoral practice and the very presence of pastoralism. Pastoralists have responded with varying articulations of stewardship. These share consistent foundations even as their form changes. I use Anderson's (1997) idea of 'critical domestication' to underpin this analysis and show that pastoral stewardship has been, and continues to be, characterised by interpolations of order and chaos in nature and of continuity and discontinuity. With its focus on humanist ontologies of human distinction from the natural world rather than specific land use ideals, critical domestication provides a framework for critically interpreting these interpolations in landscapes where ideals such as cultivation and closer settlement have not been achieved. Allying with this framework with recent perspectives on the agency and materiality of nature, I also show that stewardship is not solely a human achievement, but is co-produced by environmental variability, plants, and domestic and feral animals such as cattle and rabbits. 


\section{Introduction}

In the rangelands of Central Australia, quintessential 'outback' country, the pastoralists whose sprawling cattle stations occupy much of the land have a strong sense of achievement in their survival in an environment characterised by low productivity, aridity, and climatic extremes. This pride often manifests itself in stewardship claims; that, through reciprocal relationships with land, pastoralists have sustained the land and have been sustained by it. Such claims evoke a sense of place, care, and of stewardship, but they are never innocent; they exist within a history of conflict over land use, land management, and indigenous land rights (Gill, 2005). Yet engendering stewardship has been and is a key plank of natural resource policy in Australia. In such contexts, vernacular forms of landholder stewardship require analysis for both their capacities and vulnerabilities (Head, 2010).

My primary aims are twofold. First I aim to articulate a concept of stewardship that goes beyond its current conceptualisation in much rural research as a bundle of attitudes and practices. I do this by considering stewardship as more fundamentally a moral stance about land use and as one that is constituted through distributed agency; in this case through the evolution of pastoral culture in concert with environmental change and the agency of nonhumans. Second, I aim to critically assess the evolution of stewardship in 20th-century Central Australian pastoralism. To meet these aims I draw upon Anderson’s (1997) concept of critical domestication. This notion provides a framework for assessing claims to practices of care that explicitly looks beyond temporal boundaries and beyond humanism. By examining key moments at which articulations of stewardship have been made in the southern Northern Territory I identify continuities across different articulations of stewardship over time. I demonstrate the importance of symbolic values associated with pastoralist beliefs and activities, the strong links of these with their 'regional sense of history and sense of place' (Burton, 2004), and the importance of socio-environmental change in the accretion of 'dwelt achievements' (Jepson et al., 2011). 


\section{Variability and the Interpretation of Arid Zone Pastoralism}

In addition to the constraints of arid zone environments pastoralism faces challenges posed by economic change, indigenous interests in land, and environmental critiques (Holmes, 2002; MacLean, 2009). Indeed, following an Australian High Court decision in 1996, in which it was found that indigenous property rights could persist on leasehold pastoral properties, pastoralists found themselves at the centre of national conflict about indigenous reconciliation (Gill, 2005). More generally, Australian rangelands have become increasingly subject to 'global values of environmental protection' (Woods, 2007, p.493) and critiques and campaigns mounted by environmentalists (Gill, 2005). Far from being an untouched 'wilderness' or timeless 'outback', Australian rangelands are characterised by high rates of plant, bird, and mammal extinction and vulnerability (Letnic, 2000). Concerns about soil erosion, pasture decline, and the impacts of feral animals have long featured in their history (Heathcote, 1987).

Moreover, while views of the inland as barren or monotonous (Haynes, 1998), arid rangelands such as in Central Australian are extremely variable in time and space. Episodic events such as a major flood, an extended dry period, or heavy grazing can shift landscapes or smaller areas to dramatically different vegetative or geomorphic states (Morton et al., 1995; Westoby et al., 1989). Rainfall itself is highly variable; annual rainfall is skewed to low totals with occasional years of high rainfall, characterised by mostly small events with occasional very large falls. Plant growth is geared towards the larger, more occasional falls and rainfall timing and magnitude influence which species germinate. Land management histories can also considerably influence the composition of vegetation (Griffin \& Friedel, 1985). Separating the influences of cattle grazing from the myriad non-grazing variables that influence plant assemblages is a complicating feature of arid zone ecology and conflicts.

Ecological interpretations that emphasise variability have been particularly influential since the 1980s. They also, as is shown below, share significant common ground with interpretations pastoralists themselves of environmental processes. However, while many arid zone ecologists have long argued the need to reform land use (Morton et al., 1995; Ratcliffe, 1947), pastoralists more often find confirmation of the value of pastoral settlement. This divergence highlights the importance of recognising the cultural contexts within which environmental knowledge develops. 
Variability helps make two important points here. First, I am dealing with conditions of always incomplete knowledge of a perpetually confounding and fluid nature (Lorimer, 2010). Second I engage with, 'temporality and movement' to produce accounts of landscape and nature (Cresswell, 2003, p.280). I enlarge upon previous historical geographies of the fate of European land settlement ideals in Australia (Heathcote, 1987; Powell, 1977) in an account of the role of the lively and complicated behaviour of non-humans in the cultural politics of land use in the Australian inland. However, I do not simply reiterate the failure of these ideals as manifest in the lack of closer settlement across the inland. Nor do I use the common yet limited lens of European adaptation to a new environment (Head, 2010). Instead I identify the distinctions between order and disorder, and between states of nature and states of civilised accommodation with nature that underpin the ideals. I trace the persistence, malleability, and reproduction of these distinctions into late twentieth century rangelands.

\section{Stewardship and domestication}

A key element of Australian environmental policy has been the aim of inculcating a stewardship ethic amongst rural landholders (Lawrence et al., 2004). The appeal of this aim has been a significant factor in the development and funding of major federal programs such as the Decade of Landcare and its successors such as the current 'Caring for Country' program. Yet research has consistently cast doubt on the utility of the concept as it has been used in policy, showing, for example, that there is little relationship between positive attitudes about environmental protection and adoption of certain land management techniques (Cary \& Webb, 2001; Curtis \& De Lacy, 1996; Curtis \& de Lacy, 1998; Pannell et al., 2006; Sayre, 2004). This is despite the fact that the same research has often found that a stewardship ethic is strong amongst rural landholders. One conclusion arising from this finding is that the concept of stewardship is of questionable utility. Echoing earlier US research (Buttel, 1992), Lawrence et al (2004) suggest that ideas commonly associated with stewardship such as protecting the environment for future generations are vague and unlikely to meet any disagreement. In part this is a function of how stewardship has been approached. The research tends to define stewardship in terms such as passing the land on undamaged and sustainability. It is tied strongly to 'best practice' land management techniques as defined by scientists and managers. The concept is then operationalised in surveys designed to elicit scores on attitudes, beliefs, and adoption - for a rangelands example see Holmes and Day (1995). 
Related research in landholder management and adoption practices, however, provides insights that suggest the potential utility of a broader concept of stewardship. Most significant is the principle that farming is a practice 'governed, informed and regulated by social processes’ (Vanclay, 2004, p. 213). Significantly landholders generally want to undertake 'good farm management', the notion of which is complex and dynamic. In this paper I use critical domestication to enlarge on the formation of ideas of 'good' management, contributing a cultural perspective to recent work on pastoral knowledge in rangelands (Gill, 2006; Knapp \& Fernandez-Gimenez, 2009).

Thus stewardship is uncoupled from any particular set of practices or ways of doing farming or grazing. Further, I argue here, stewardship as a focus of research should be uncoupled from any particular temporal context and associated disciplinary framings of land and environment. Stewardship is better seen as constantly reformulated as landholders struggle to accrue the cultural capital needed for legitimation of what stands as looking after land at particular junctures of time and space (Harrison et al., 1998; Richards \& Lawrence, 2008). In this context much existing rangelands survey-based social research such as Holmes and Day (1995) invites further scrutiny of pastoralist conceptions of responsibility, production, environment, and the relationships and tensions between them.

Building on the idea that stewardship is primarily about 'looking after the land' (Worrell \& Appleby, 2000), I use stewardship to refer to landowners' sense of what constitutes responsible and moral land use and management. There is, however, no reason to assume that notions of care and connection are innately associated with morality, goodness, and openness to others (Howitt \& Suchet-Pearson, 2006; Ingold, 2005). Indeed the opposite may be true 'a seemingly commonsensical orientation towards the future, in a society built upon destruction, enables regimes of violence to continue their work while claiming the high moral ground of making a better future' (Rose, 2004, p. 15). I use morality in the descriptive sense often used regarding moral geographies; 'its use being informed by a[n]...assumption that senses of moral order are produced through environmental and spatial practices that are always bound up with relations of power' and by 'suspicion regarding any claim to being able to define morality' (Gregory et al., 2009, p.479). In this use stewardship is more flexible and not tied to modern conceptions of sustainability, care, or best practice. This use is in contrast to a normative approach to morality concerning stewardship such as invoked by 
Freudenberger and Freudenberger (1994). I conceive of landholder stewardship as being always under construction, transitory, as being explicitly historically and spatially situated, and as morally ambiguous. Moreover, I argue, nature is similarly not a backdrop to stewardship, but is a key part of the contingencies which constitute it.

To open up pastoral stewardship for critical inspection I will draw on Anderson's notion of critical domestication (Anderson, 1997). At first glance conventional notions of domestication founded variously in evolutionary perspectives, the expansion and/or cultivation of plants and animals, or on the application of agrarian ideals seem particularly relevant in Australia (for example see Crosby, 2004; Powell, 1977; Tonts et al., 2010). Teleological ideas of improvement were key elements of the biblically-justified, empirebuilding brand of stewardship popular as the British established Australian colonies and sought to establish agriculture and grazing across Australia (Heathcote, 1965). Anderson's point, however, is that domestication has a deeper and more complex history. The exploration of this history has been inhibited by uncritical adherence to an evolutionary conception of domestication and which is focused on human agency and on humanity as achieved by an ascent out of nature (Anderson, 2007).

Anderson characterizes the scope of critical domestication:

[an] extensive framework of ideas about 'human' uniqueness and dominion, a key material basis of which...lay in domestication of the nonhuman world. This was a source of ideas about perfectibility under selection practices, of improvement towards the goal of cultivating the wild, of mitigating backwardness, of reigning in and 'fixing' wildness to a settled point (Anderson, 1997, p. 475).

This takes domestication beyond a model of 'cultural transfer' from the imperial centre to the antipodes to examine how it plays out in amid various social relations. This draws attention to concrete practices by which the wild is civilized and to the 'modalities of power' that are part of such processes This civilizing is not necessarily only in the sense of material transformation, but also in the sense of the wild being drawn 'into...the boundaries of the known (Anderson, 1997, p. 475 \& 481). Seeing domestication in a deeper temporal setting mitigates against reproducing domestication as framed at the time of colonization. Instead of being a 'transhistorical process of evolution's unfolding' it has 'diverse underpinning 
moralities, contradictory manifest forms, and is open to rupture and reversal' (Anderson, 1997, p.481).

In Australian rangelands where pastoralism continues to be challenged by alternative values, interests, and economic pressure (Holmes, 2010), this concept of domestication is relevant for at least three reasons. Primarily, it expands the timeframe within which to consider pastoral stewardship and thus see it as emergent rather than fixed. It can be used to consider diverse historical settings and processes by which realms of human/civilisation/order and nature/wildness/chaos have long been made, negotiated and remade as life sources are transformed and brought from chaotic 'agrios' into a civilised 'domus'. This is particularly relevant to extending the scholarship of rangelands where the environmental transformations and arrival of 'civilisation' wrought by the manifestations of agrarian visions and policies of 'improvement' (Meinig, 1988) - closer settlement, a resident yeomanry, cultivation, a - have largely not eventuated except perhaps in increased fencing and bore development to meet modern herd management requirements (Anderson, 2007; Head, 1999). Instead 'wildness' remains in the sense of extremely sparse settlement, predominant reliance on 'natural' pastures, and the influence of the environmental variability outlined above. In vernacular terms we have the 'wilderness' of Outback Australia, not the prosaic paddocks and small towns of cropping belts. Yet, as I argue in this paper, pastoralist claims to stewardship over time rely on representations of people, cattle, and land that embody many of the tropes of improvement and domestication. This embodiment, however, is in often contradictory ways in which order is in tension with wildness as much as in transcendence. Eschewing linearity and necessities of form yet acknowledging their power in the formation of dominion, critical domestication can help make sense of such contradictions and tensions. Second, over time this process of making and distinguishing between these binary realms has 'drawn on a mix of moralities' (Anderson, 1997, p.478), well suited to a critical analysis of stewardship over various time periods. Third, the concept is not human-centric, its forms are characterised by the distributed agency of both humans and non-humans.

To apply this concept of critical domestication I trace the reverberations of selected key moments to 'acknowledge ontologically the vitalism and materiality of non-human entities' (Anderson, 2003, p. 425; Nygren \& Rikoon, 2009; Whatmore, 2002) and the 'constitutive force of things in social and political life' (Braun, 2008). To examine the role of variability in constituting culture-natures (Hinchliffe, 2008; Whatmore, 2006), my focus is on certain 
large-scale events, the various roles of selected animals, and micro-scale biophysical processes. Variability and agency are key constitutive elements of the assemblages of nature and culture in CA, and, I argue, important in iteratively shaping pastoral stewardship. This historical-geographic perspective on the "coproduction of socionature" (Bakker \& Bridge, 2006, p. 19) is valuable for a sense of materiality in which the "things... that make a difference in the way social relations unfold are not pre-given substrates that invariably enable and constrain social action, but are themselves historical products of material, representational and symbolic practices" (Bakker \& Bridge, 2006, p. 18). The vitality of things other than humans and their capacity to act and have an effect is not an essential property of them (Braun, 2008) but something that varies according to the times within which they act, the encounters with humans that they have, and their particular expression within both these sets of parameters (Jones \& Cloke, 2002). Their agency is an 'emergent property of network associations rather than a property inherent in discrete entities' (Bakker \& Bridge, 2006, p.19). This approach is not without antecedent in cultural ecology (Leff, 1985) but differs in ontology, including in its treatment of the agency of nature which, as used here, does not precede culture (Head, 2007; Ingold, 2000).

\section{Methods}

My empirical material comprises key 'moments' of stewardship over the twentieth century as identified through fieldwork and historical research in the Alice Springs Pastoral District (ASPD) in the southern NT. It encompasses observations of environmental change in the early and mid twentieth century. I also draw on material relating to a significant drought in the 1960s when there was a significant encounter between pastoralists and early proponents of ecological concern about rangelands. I trace resonances of this encounter into the late 20th century. Finally, I draw upon a high profile case where pastoral stewardship was aligned with environmental concern during the Australian Decade of Landcare. This program, now significantly altered (Lane et al., 2009), ran from 1990-1999. It was a groundbreaking program with the overall aim of promoting sustainable rural land use (Curtis \& Lockwood, 2000). Its most significant element has been landholder groups using government and their own resources to tackle land management problems. In CA this occurred through the formation of a pastoralist Landcare group (the Centralian Land Management Association, CLMA) which promotes changed pastoral land management and which has acted as a public voice for pastoralists (Gill, 2004). 
I draw upon ethnographic fieldwork, interviews with pastoralists, and oral histories recorded by the author and held by the Northern Territory Archives Service (NTAS).

The fieldwork component of the study examined pastoralist conceptions of nature and environment, their relationships to land, and the processes by which these relationships developed and are sustained. This fieldwork included semi-structured interviews with 34 pastoralists on 16 stations. This is approximately $22 \%$ percent of the stations in the ASPD. Five retired pastoralists and three staff members of the CLMA and Northern Territory Cattlemen's Association (NTCA) were also interviewed. The fieldwork also included travelling around stations with pastoralists in the course of their work, working (mustering, branding, trucking cattle, vehicle repair, water drilling, 'bore runs', fence repair, butchering etc) on stations for up to several days, and attending Landcare meetings and field days. A field journal was kept over a two year fieldwork period and I also draw on documentary sources held by the NTAS, the National Archives of Australia, and the Arid Zone Research Institute in Alice Springs. In order to make sense of this disparate information coding was used to break the information down. This essentially involved an iterative and reflective process of triangulation across the sources and classifying the information according to categories derived both from the research aims, from ongoing research activities and the material itself (Patton, 2002). For example, the statements, concepts or ideas about land expressed by pastoralists were captured in a range of evolving categories. This facilitated historical contextualization of recent events and meanings. The key 'moments' and the selected data that I present in this paper emerged from this analytical process. In this paper each 'moment' is necessarily concise, further or parallel details for themes such as pastoral experiential knowledge and the operations of the CLMA can be seen in Gill (2003; 2004).

\section{Pastoral Stewardship: Chaos and Order}

Rain, plants, renewal, and complexity

From 1958 to 1965, the Central Australian pastoral industry experienced the longest extended period of below median rainfall since 1874, when records began at Alice Springs (Figure One). It was a significant event for the development of pastoral culture in relation to environmental change (Ling, 2010) and the 1958-65 drought and surrounding events resonated in pastoral culture into the 1990s. 
Pastoralism came under considerable criticism at the time and debate included the possibility of destocking the region (Northern Territory Land Board, 1964). Critics included the government botanist, George Chippendale, who undertook some of the first Central Australian research on the impacts of cattle grazing (for example Chippendale, 1963). The Central Australian Pastoralists' Association argued that, in contrast to such 'technically sound' but unseasoned people, pastoralists knew the true productivity of the land from long experience and invited the NT Administrator to visit properties where pasture was abundant on previously denuded land:

To the men who have worked this country for years and seen it respond after previous drought conditions, there is nothing remarkable in this, but only a normal cycle of nature (National Archives of Australia: F1, 972/3720, CPA Secretary to NT Administrator 18/5/1962).

These views were echoed in pastoralist verbal submissions to the NT Land Board's 1964 inquiry into the drought ${ }^{1}$. For example, one told the Land Board:

It's marvelous to see the growth of feed and the fattening propensity of the feed mostly after a prolonged drought, especially if we get good rain. I know myself after all...this drought in 1962 we got below average rainfall but we got the bullocks fattened in a very short time. It picks up very very quickly in this country.

Not only is the country seen as resilient but, as the above statement implies, and as other pastoralists state, extended and close experience of the land is required to develop knowledge of its resilience. Such invocations of faith in the land and descriptions of previous cycles of drought and recovery are articulated by many pastoralists who gave evidence. Consistently, they argue for a powerful collective pastoral knowledge of these cycles in Central Australia, for individual knowledge formed by experience but tempered by length on the land, and for deference to 'old timers' whose experience exceeded that of the current generation.

The rains of 1966, and subsequent high rainfalls from 1973-1978 that allowed cattle numbers to expand far in excess of previous numbers, brought changes in the vegetation (Griffin \& Friedel, 1985) that vindicated pastoralist faith in the land. In their view the country 'came back'. This refers to faith and belief in the resilience of country and its ability to again more 
produce pasture and other growth following apparent barrenness. As a former pastoralist wrote at the time, pastoralists didn't leave because they had the 'faith to struggle on because they...believe in the country and its ability to recover (Anonymous, 1966, p.27). In this view, the country is reborn, its fertility undamaged by drought or by cattle. While the idea that country 'comes back' is not uncontested among pastoralists today (Gill, 2004), as I discuss in other contexts below, the underpinning ideal of reciprocity between pastoralist and country is evident in various other expressions of stewardship including more recent ones.

The 1970s rains triggered wide-scale establishment of shrubs that remains evident. North of Alice Springs, densities of mulga were recorded at up to three thousand individuals per hectare (Griffin \& Friedel, 1985). While ecologists suggest that the shrub establishment was as much a function of the ecology of historically intense cattle grazing (Griffin \& Friedel, 1985), the vegetative growth after the drought is taken by pastoralists as evidence of resilience and of their knowledge of the land relative to those they see as transient outsiders. For example, in response to 1990s allegations of overgrazing, a retired pastoralist said:

I remember in our sixties drought...we had botanists telling us how the country's been buggered by overstocking and it would never ever recover. And of course...none of them came back. When it did rain... this country came back better than it ever was. Now, the old, old fellows that were here in the thirties drought used to say: 'Don't worry boy, she'll recover. It's good country. When the rains come she'll come back. And it did (NTAS Oral History TS922).

This view was also evident among other pastoralists in the 1990s. For example, during fieldwork a pastoralist in his fifties who had reduced his stocking rates by over fifty per cent since the 1970s peak, nonetheless argued that 'you cannot overstock, the country will kill you before you kill it'. He emphasised the power of natural processes in driving change - ' you can't hold back nature' - and the long time scales of observation needed to have any chance of comprehending what was occurring: ‘you can't tell anything in five or ten years what's going on in the country, because you can't tell what the country's doing'. Like other pastoralists, in a refinement of the 'country comes back' argument, he argued that discerning relationships between stocking history, rain, and the nature of vegetation was extremely difficult. He suggested that unpalatable species may germinate after one rainfall event causing him to think the country was 'buggered', only to have the area produce palatable pasture species in following rain. Similarly, pastoralists argued, and have long and 
consistently done so, that they observe that unstocked country can be in just as poor vegetative condition as stocked country, and that stocked country can be in good condition while unused country is bare. In separate conversations the young adult sons of the pastoralist above broadly agreed. While they conceded that that the environment is multidirectional, they contended that its complexity demanded direct experience in order to have any chance of understanding. Even then, they noted, it was difficult to explain vegetation change. Pastoralists' observations of variable vegetation responses under different grazing pressures confirm landscape unpredictability.

In the variability of vegetation, many pastoralists talked about seeing chaos, unpredictability, and abruptness in vegetation change, often associating specific case of vegetation growth particular episodic events Other examples included sites such as those described above, where the composition of vegetation was seen as unpredictable, varying from season to season and between 'desirable' and 'less desirable' pasture species. This process of observation and associated knowledge claims is ongoing and is not limited to an older generation of owners. Younger pastoralists also demonstrated and discussed the importance of observing environmental change as they travelled, camped, and worked around the stations in shaping their understanding of country.

What should we make of these pastoralists' perspectives on change? We can certainly say that while pastoralists have not mitigated wildness, they have brought it within the boundaries of the known and used this to mark themselves off from outsiders. Moreover, the above material could readily be used to valorise local knowledge, long-term commitment to place, humility in the face of nature, and a commitment to coexist with unpredictability. However the observation during fieldwork of one pastoralist, at the forefront of reshaping pastoral stewardship in the 1990s, that certainty was impossibility as 'the country is too young to know' are revealing. This resets the clock of history to the beginning of pastoral settlement and experience and places pastoralists and their cattle at the centre of the cosmos and as the focus of a future-oriented time. In this respect it is a good example of the Year Zero identified by Rose as a key element in colonial and ongoing violence to land and people (Rose, 2004). It reveals a monological prospective in dialogue with itself even as it has the appearance of a more thoughtful and ethical engagement with nature. 


\section{Gardening the Centre}

The perspectives on cattle and environmental change above highlight two key general points. First, that unpredictability and change is a key constituent element of this manifestation of pastoral socio-nature. Second, within this form of socio-nature cattle are, at worst, neutral in their impact on country. Consistent with critical domestication, there is a parallel but contradictory manifest form of this expression of pastoral stewardship based in reciprocity amid unpredictability. They key elements of this parallel form are linearity in environmental change and the role of cattle as agents in materially improving country. Pastoralists see the agency of cattle in soil disturbance which provides hoof indentations and breaks up the soil surface to facilitate seed and moisture penetration of the soil ${ }^{2}$. Pastoralists commonly referred to the role of cattle in 'opening up' vegetation and to seeing seeds and seedlings in hoof prints and vegetation growing on bare areas following the introduction of cattle to an area. This was evident in one older pastoralist's comment that stocking is 'just like ploughing the land' and that of another in his thirties who argued that cattle had caused a transition from unpalatable spinifex grass to palatable pasture species on their property. Another commented that when land left the pastoral estate and cattle were removed, for example when land was transferred to Aboriginal ownership, it went backwards to being 'wild country'.

The belief that cattle 'improve' the land implies, that for pastoralists, not only do cattle change the landscape for the better, they actually play a role in creating it and rendering it culturalised 'country'. Pastoralists' evidence to the 1964 Land Board hearing in Alice Springs and the views of the late prominent pastoralist Ted Hayes illustrate the ingrained nature of these beliefs in pastoral culture and their deep historical roots. For example, Hayes claimed that the Todd River valley was transformed from 'bulldust' to some of the best stands of grass and top feed in the district following stocking (Anonymous, 1987). According to Hayes, the 'cattle created a different sort of topsoil texture which allowed moisture to penetrate and seed to set' (Anonymous, 1987 p . 26-27) ${ }^{3}$.

A revealing example of the improvement of country in pastoral historical memory is found in Robinson's account of her family’s settlement at Glen Maggie, 125 kilometres north of Alice Springs (Robinson, 1999). This is an account of 'improvement' that can be pinpointed to a particular rainfall pattern. It illustrates how the memory of such events is carried within pastoral families and reproduced for wider audiences. In Robinson's account of her grandmother's observations, the country improves with cattle grazing: 
Liz noticed an improvement in grasses and...shrubbery. Because she was a gardener...she believed the cattle were responsible. Their hooves broke up the topsoil and their bodily waste nourished the soil...Every hoof indent left a cradle for new seeds... and held little pockets of water (Robinson, 1999, p.43).

Amid fragmentary historical records of arid zone environmental change (Lunney, 2001) such pieces of information become significant. Amongst pastoralists they form part of a collective memory as husbanded by senior and elderly members of the pastoralist community such as Robinson; she herself grew up hearing the story from her grandmother (J. Robinson, pers. comm. 8/1999).

The importance of particular events in CA can be also be discerned from the Nicker/Robinson account of environmental change. Liz Nicker's observations can be dated to the period 1914-1930 (Robinson, 1999). The time of the Nicker family's arrival happened to coincide with a period of below median rainfall (Figure one). The two vertical lines delineate the Nicker's period at Glen Maggie. It can be seen that rainfall was low for the first five years of their time at Glen Maggie. This was followed, from 1920, by four years of exceptionally heavy rainfall.

Such rainfall peaks are associated with large-scale regeneration and growth of vegetation (Griffin \& Friedel, 1985). From this rainfall evidence that the family memory of cattle improving the country is associated in time with a period in which large-scale vegetation growth would be expected due to rainfall. This association between a specific rainfall period, a conclusion drawn at the time (cattle are 'good for country'), and the subsequent influence of this observation, point to the role of events at a local or regional level in the construction of knowledge systems and of pastoral culture. The narrative of 'improvement' is widespread and persistent, and has shown itself to be resilient in the face of contradictory or more nuanced scientific evidence and information presented over decades by government and other scientists.

In these narratives, cattle are modifying the landscape and the landscape is responding to the presence of pastoralism. Cattle (re)create the landscape, they make it what it has become today. In their 'gardening', cattle mimic and enhance natural processes. Cattle enact 
stewardship; they are not only good for country, they make country good. In so doing they echo more linear pathways of improvement through cultivation for agriculture and rein in agrios in favour of a pastoral domus but in a form distinct from that embodied in living with chaos.

Redrawing the boundaries; Landcare, rabbits and modernising management.

In the 1980s pastoralists formed a Landcare group, the CLMA, which operates to the present day. This group has been very successful in attracting funding and raising the profile of pastoral land management. It has also acted as a key conduit by which NT and national land management reform programs have reached pastoralists. This success has included winning a national Landcare group award in 1998 in competition with almost 5000 groups. Pastoralists are not always united in their views and since its inception, the CLMA has trodden a line between advocating land management reform and presenting its activities as the inevitable evolution of long-held and authoritative pastoral stewardship. Inevitably perhaps, its early days were characterised by defensiveness (Gill, 2004).

In the 1990s a younger generation of pastoralists began to modernise the CLMA. This did not however lead to a strategy of demarcating a progressive present from a past of poor management. Instead, pastoral stewardship in the Landcare era has been presented as a continuation of the past. Pastoral stewardship, repackaged consistently with contemporary sustainability, has been presented as unchanging and as inherent to pastoralists' identity, practice, and interests. Some instances of this come from a 1999 CLMA symposium. A pastoralist from a long-standing family in the region argued that his family at least had always been conservationists of some sort noting that in the early 20th century criticism of their stock numbers as 'understocking...was based on southern opinions [that] failed to recognise that understocking prior to the sinking of bores was the only safeguard for the survival of...the fragile land' (Hayes, 1999b) ${ }^{4}$. Similarly he argued that criticism of overstocking in the 1960s was misplaced as pastoralists were reducing stock numbers. He went on to say that 'we are at heart conservationists...We are aware of the fact that the property has to be left in as good a condition as we found it'. The CLMA president, a younger member of the same family also spoke of the stewardship credentials of pastoralists: 
Whether you call them the stewards of the land or any other trendy name the fact remains they are the ones who have put generations of work and investment into the region. They have the experience of the dramatic changes...that are natural to the region (Hayes, 1999a).

These Landcare-based narratives draw on complexity and cyclical change as discussed earlier in relation to short-term and long-term environmental change. However, Landcare practices and discourses breathe new life into older ideas of improvement and linear progress, marrying them with ecological conservation and improved grazing management. This is evident in various ways, not least in CLMA's rabbit control programs and in grazing management programs. In these two programs in particular, animals, rabbits and cattle, remain key agents in enacting pastoral stewardship, working against and within nature respectively such that cattle continue to make country good as agents of improved and increasingly ecologically-based management.

Here I use rabbit control to show how management is aligned with contemporary resource management norms. In Australia, rabbits are regarded as a major feral pest causing land degradation, costs to primary industry, and adverse impacts on native fauna and flora. Rabbit control projects have been a key part of the CLMA operations, and have at times dominated their budget and public profile (Gill, 2004).

The CLMA emphasises the environmental impacts of rabbits (CLMA, 1997). Such impacts can scarcely be argued with. These same impacts, however, can also be attributed to cattle, although on this matter there is a relative silence in CLMA discourse (Gill, 2003). More significantly, as rabbits are singled out as agents of ecological villainy they become key to modernising the binary opposites of order and chaos in pastoral culture. Rabbits are a necessary part of the process of 'monological transformation... essential to successful colonisation' (Rose, 2004, p.151); necessary in the sense that the demarcation and characterisation of order requires its corollary, disorder. If the successful reproduction and legitimating work of pastoral stewardship is to be continued in an era when older notions of stewardship through productive use and improvement have less traction, then new realms of disorder which can be domesticated are required. Rabbits do this work.

Connecting, by CLMA, past and present stewardship through rabbit control is a twofold process. First, as is evident in the CLMA's 1997 entry for the nature conservation award in 
the national Landcare awards (CLMA, 1997), the CLMA positions pastoralists as experienced people who physically engage with nature. This compares with outsiders, such as urban newcomers who merely talk about what should be done on the basis of book learning. The entry notes that 'rabbits are beatable, but just talking about it isn't sufficient and 'we could talk about rabbit control for another 20 years or we could start doing it. The CLMA chose to start' (CLMA, 1997, no page numbers). Second, rabbit control is characterised as a key practice of environmental care by, for example, positioning rabbits as an 'environmental disaster' (CLMA, 1997). The parameters of this disaster are competition with native animals, threats to rare plants, loss of shrubs, poor quality species composition due to selective rabbit foraging, and erosion due to denudation (CLMA, 1997). The CLMA response has been to encourage landholders to manage rabbits, to support these landholders with advice and resources, and to monitor the impacts of control work. To undertake this work the CLMA obtained funding through Landcare programs. The primary means of control were warren destruction with heavy machinery, fumigation, and the release of fleas as vectors for two diseases, myxomatosis and rabbit haemorrhagic disease. A key element of the rabbit projects were associated monitoring programs. These projects attracted national interest and funding and in 2000 the CLMA won the national Landcare Research award for this monitoring work. The monitoring projects were a key means by which a dimension of ecological care became more closely integrated with pastoral stewardship and then projected to a wider audience through various means such as pamphlets aimed at the general public, media, the Alice Springs show, as well as the Landcare awards. The monitoring was a credible program with treatment and control sites aimed at establishing baseline information regarding the impact of rabbit control on vegetation, predators, and native mammals (CLMA \& Parks and Wildlife Commission NT, 1996).

In reducing rabbit numbers pastoralists see themselves as enacting the stewardship of broader national interests in both ecological conservation and sustainable grazing (Cadzow, 1993). While the CLMA promotes rabbits as destructive, implicit in the narrative and practice of rabbit control is a productive tension for pastoralists. In CLMA representation of rabbits and their chaos is that there is an alternative - the orderly pastoral landscape brought about by the mobilisation of pastoral ideals and labour. This is a landscape not only ordered by the markers and practice of long habitation but is also increasingly evidenced by CLMA promotion of scientific rabbit management as well as modern management tools and approaches such as Environmental Management Systems and land systems based grazing 
management (Gill, 2004). These tools bring a new vision of pastoral landscape order based on ecological and agronomic science predicated on the possibility of rational mastery of nature (Adams, 1997). Thus do pastoralists continue to seek to 'reign in the wild' and 'mitigate backwardness' even as they require an ongoing tension between 'agrios' (chaos/wildness) and 'domus' (order/home) (Anderson, 1997) in difficult and variable rangelands landscapes that resist overt transformation. In this tension lies the space for the ongoing production and seamless evolution of pastoral stewardship

The representation of unbroken pastoral stewardship continues in a more recent CLMA project that connects past and present. This is a resurvey of sites surveyed during the 1960s drought by the New South Wales Soil Conservation Service (Condon et al., 1969) . Between 1993 and 1995 one of the authors of the 1960s research resurveyed many of the sites with support from the National Landcare Program (Cunningham, 1995). The findings were of overall improvement on criteria such as soil stability, presence of perennial species, and pasture cover. The key findings of 'improvement' remain prominently listed on the CLMA website (CLMA, 2009) and the 1997 biannual report (CLMA, 1997) that formed the basis of the 1998 National Landcare award includes photos demonstrating improvement between 1965 and the time of the resurvey. In the complexity of environmental change in CA, such data as yielded by the methodology of this resurvey are likely of little scientific validity. It does however provide evidence of change that is consistent with broader pastoral understandings of change in the landscape, the role of cattle and their sense of stewardship. Its context encompasses the experience and interpretations of change discussed earlier as well as other contemporaneous pastoralist interpretations of the neutral or positive role of cattle associated with pasture condition monitoring carried out by the NT government (Gill, 2003).

\section{Discussion}

Critical domestication is concerned not so much with particular manifestations of ideals, such as cultivation, but processes by which humanist ontologies of human distinction from the natural world are realised and states of civilisation attained. My aim here is in part to emphasise the plurality of such states, to explore their contingency, realisation, and ongoing political significance. I do this in a region where colonial ideals of land use that have been understood to mark such states of civilisation have manifestly not been met. Yet, this Central Australian study demonstrates how settlement ideals associated with landscapes of cultivation and a classically humanist trajectory of development from a state of nature have persisted in 
diverse forms and in landscapes where the ideals are usually understood to have failed. For pastoralists, humanity is not realised by simply transcending the natural or the animal (Anderson, 2003) but by entering into relationships with these. They have forged long term individual and collective relationships with cattle, rabbits, plants, and rain to rein in wildness.

For pastoralists this is achieved in two distinct and seemingly inconsistent ways. First, they harness experience, observation, persistence, and inter-generational narratives of unpredictability and chaos in nature to build reciprocity with nature without agricultural transformation. Pastoral land settlement, long-term experience, patience, and management interventions bring order and are contrasted with the chaos and state of wildness of land without people and their cattle. This is not to say, however, that wildness is erased. On the contrary, for pastoralists, the ascent out of nature, the creation of a pastoral domus, occurs precisely through specific relationships in time and space with nature, both with specific biophysical events and processes and with successive events and cycles of environmental change over longer periods. Various animals by whose presence or removal order is created, maintained or wrested back, materially or symbolically, are also central players. Paradoxically agrios is held at bay by its very emplacement within pastoral culture. Temporal scale is key to this emplacement. Individual events and fluctuations attain meaning only within larger and cyclical time scales. At such scales, pastoralists find affirmation of themselves and their occupation of land, and reciprocity with the land.

Second, alongside pastoral engagement with chaotic nature beyond the transformative capabilities of humans and cattle is a view of nature as linear and malleable. Over the latter half of the twentieth century pastoralists have represented the role of cattle in altering the land as akin to natural processes and as part of a normative trajectory of improvement. In this perspective, cattle work within nature and imprint pastoralism into the very fabric of the land and thereby realise and enhance value; pastoralism and the presence of cattle become part of the land and thereby 'nature' and 'natural'. 'Improvement' itself is thus seen as a natural process but not only this; it is achieved with nature, as cattle work in concert with soils and plants to improve country. For pastoralists cattle are not only 'good for country' as they sometimes say; they make country good, materially and symbolically.

The work and positioning of the CLMA allows pastoralists to connect these two perspectives to simultaneously assert unbroken stewardship of CA while also reinventing it. Through the 
CLMA, pastoralists continue to draw on long term experience of change and persistence to position themselves as knowledgeable and deeply-rooted insiders in contrast to feckless and fickle outsiders. At the same time they draw on evidence of 'improvement' since the 1960s, their ability to manage the destabilising presence of rabbits, and, more implicitly, their management of cattle. For the pastoralists, by the 1990s, CA's 'state of nature' has been brought into an ordered fold of human endeavour and accommodation and rabbits represent a threat to this.

In the process of controlling rabbits, pastoralists reveal much about the boundaries they draw to delineate what belongs and what doesn't in CA. Rabbit control and monitoring by pastoralists and the CLMA are key means by which pastoralists reproduce and modernise the order that pastoralism brings. Crucially this is done through allying the techniques and ideals of ecological conservation with long-standing pastoral identification as stewards. Pastoralists thereby not only draw boundaries between pastoral and other natures, but they are also contesting images of themselves as anachronistic remnants of more exploitative times and are seeking to reclaim the moral high ground, now framed less in productivist terms and more in ecological and other values.

Pastoral stewardship, then is not amenable to being simply read off from practices or beliefs captured at a particular time. Stewardship is a better understood as an achievement that has temporal and experiential depth as well as collective and individual dimensions. It is also not solely a human achievement - particular events such as rainfall or erosion events, animals, and environmental processes are intertwined with variable social contexts and moralities. These entanglements facilitate both consistency and change in pastoral culture and stewardship. Notions of improvement, for example, justify early settlement, underpin a sense of how cattle belong in CA, and are enacted by cattle themselves. Yet, improvement ideals also underpin more recent practices of ecological care such as the control of rabbits and longer term recovery from the 1960s drought alongside continued pastoral land use. Such variable practices of pastoral care over long time periods demonstrate the entanglement of stewardship as care in a range of complex and ambiguous relationships. They also show how a focus on care, uncritically conceived, may miss the significant political and cultural work that stewardship is doing over time. This analysis of various articulations of what could readily be interpreted as pastoralist 'care' and as embodying worthy relationships to land and place shows that these are always entwined with the politics of land. At all times, despite its 
changing moralities and forms, pastoral stewardship over the latter half of the twentieth century is part of a persistent framework of domestication by which wildness is simultaneously 'reined' in and accommodated, and pastoral dominion asserted.

\section{Conclusion}

To address my aim of critically examining the evolution of stewardship in CA I have undertaken a biographical analysis of pastoral stewardship over several decades of the twentieth century. This analysis has shown the important role of various forms of chaos and trajectories to order in constituting and reconstituting stewardship over time and the ongoing significance of their apparently paradoxical but parallel and often interpolated persistence. The specifics of the interpolation of continuity and discontinuity generate and maintain meaning that supports internal cultural cohesion and does political work in struggles over land. The concept of critical domestication provides a framework within which I have been able to place the development of pastoral stewardship in a deeper temporal and cultural context, demonstrating that it is not a given 'transhistorical process' that unfolds but is a ‘political activity embedded within concrete human practices’ (Anderson, 1997, p.481). In moving beyond a paradigm of interpreting inland settlement through cultural transfer and adaptation to one that recognises pastoralists' relationships to land and place, we should not uncritically privilege claims to belong and to know nor should we deploy local environmental knowledge without awareness of its cultural and historical contexts.

Finally, stewardship is not only embedded within human practices but also within the actions and effects of a range of non-humans such as rabbits, cattle, plants, soil, and rain. Rural stewardship is more than a bundle of attitudes held and practices enacted. In CA, environmental change and the actions of animals make a difference to the development of stewardship and to the institutions that give expression to it. Such effect does not, however, arise from any essential properties of these non-humans; it varies according to the times, to the nature of encounters, and to the expressions of their capacity to act. This suggests, not the end of stewardship's usefulness to analysis of land use and management, but the potential of a reinvigoration of analyses of rural stewardship. Such a reinvigoration would are encompass the coproduction of the socio-natures that constitute forms of stewardship at particular junctures of space and time. 


\section{Acknowledgements}

I am grateful for the assistance of Kay Anderson, Gavin Bridge, Cathy Robinson, John Cook, Lesley Head, and Deborah Rose. The research was supported by Land and Water Australia and a NTAS History Grant. The paper benefitted from a workshop funded by the Institute of Australian Geographers. 


\section{Notes}

1. A transcript is held at the Department of Resources library in Alice Springs.

2. While grazing certainly brings environmental change, the role of cattle-induced changes in soil characteristics is less clear, is likely multi-directional, and may even be negligible (Doudill et al., 1998).

3. Long term exclosures provide evidence for such claims that is equivocal at best (Gill, 2003).

4. The reference to 'southern opinions' derives in part from 1863-1911. By the1890s large pastoral companies had failed and low capital operators, including the Hayes, moved in. Historically, pastoral settlement was characterised by differences between optimistic government plans and settlers' experience of the environmental limits (Heathcote, 1965). It is quite feasible that the Hayes were criticised for understocking. Pastoralists now perceive that 'outsiders' criticise them for overstocking and continue do so without experience of arid environments.

5. I have presented Alice Springs data as data for the nearest (13km) rainfall station to Glen Maggie, Aileron, only exists from 1949. There is a significant correlation between Alice Springs and Aileron rainfall (Kendall's tau-b $=0.546, \mathrm{p}<0.001$ ). 


\section{References}

Adams WM 1997 Rationalization and conservation: ecology and the management of nature in the United Kingdom Transactions of the Institute of British Geographers 22 277291

Anderson K 1997 A walk on the wild side: a critical geography of domestication Progress in Human Geography 21 463-485

Anderson K 2003 White natures: Sydney's Royal Agricultural Show in post-humanist perspective Transactions of the Institute of British Geographers 28 422-441

Anderson K 2007 Race and the Crisis of Humanism Routledge London

Anonymous 1966 Who said the Centre was dead? Inland Review 1 17-27

Anonymous 1987 At home on the range: the experience of an NT cattleman NT Rural News November $25-27$

Bakker K and Bridge G 2006 Material worlds? Resource geographies and the 'matter of nature' Progress in Human Geography 30 5-27

Braun B 2008 Environmental issues: inventive life Progress in Human Geography 32 667679

Burton R 2004 Seeing Through the 'Good Farmer's' Eyes: Towards Developing an Understanding of the Social Symbolic Value of 'Productivist' Behaviour Sociologia Ruralis 44 195-215

Buttel F 1992 Environmentalization: origins, processes and implications for rural social research Rural Sociology 57 1-27

Cadzow R 1993 Caring for the centre Australian Journal of Soil and Water Conservation 6 14-20

Cary J and Webb T 2001 Landcare in Australia: community participation and management Journal of Soil and Water Conservation 56 274-278

Chippendale GM 1963 Pasture Deterioration in Central Australia Journal of the Australian Institute of Agricultural Science 29 84-89

Clewett J, Smith P, Partridge I, George D and Peacock A 1999 Australian Rainman Version 3: An Integrated Software Package of Rainfall Information for Better Management Department of Primary Industries Brisbane

CLMA 1997 Biennial Report 1995/6 1996/7 CLMA Alice Springs

CLMA 200920 Years of Achievements http://www.clma.com.au/ Accessed 4/9/2010

CLMA and Parks and Wildlife Commission NT 1996 Monitoring for Rabbit Calicivirus Disease: Site Establishment CLMA Alice Springs

Condon R, Newman J and Cunningham G 1969 Soil Erosion and Pasture Degeneration in Central Australia Soil Conservation Journal 25 47-91

Cresswell T 2003 Landscape and the obliteration of practice in Anderson K, Domosh M, Pile S and Thrift N eds Handbook of Cultural Geography, Sage, London 269-283

Crosby AW 2004 Ecological Imperialism: The Biological Expansion of Europe 900-1900 Cambridge Univsersity Press New York

Cunningham G 1995 Report on the Resurvey of Rangelands Sites in the Alice Springs Area 1993-1995 Centralian Land Management Association Alice Springs

Curtis A and De Lacy T 1996 Landcare in Australia: Does it make a difference? Journal of Environmental Management 46 119-137

Curtis A and de Lacy T 1998 Landcare, stewardship and sustainable agriculture in Australia Environmental Values 7 59-78 
Curtis A and Lockwood M 2000 Landcare and Catchment Management in Australia: Lessons for State-Sponsored Community Participation Society \& Natural Resources $1361-73$

Doudill A, Heathwaite A and Thomas D 1998 Soil water movement and nutrient cycling in semi-arid rangelands: vegetation change and system resilience Hydrological Processes 12 443-459

Freudenberger D and Freudenberger C 1994 Good Relationships: Ethical and Ecological Perspectives of Rangeland Management The Rangeland Journal 16 321-332

Gill N 2003 Environmental (re)education and local environmental knowledge: Statutory ground-based monitoring and pastoral culture in Central Australia The Rangeland Journal 25 85-104

Gill N 2004 Politics within and without - The origins and development of a rangelands Landcare group Australian Geographical Studies 42 135-151

Gill N 2005 Life and Death in Australian 'Heartlands': Pastoralism, Ecology and Rethinking the Outback Journal of Rural Studies 21 39-53

Gill N 2006 What is the problem? Usefulness, the cultural turn and social research for natural resource management Australian Geographer 37 5-18

Gregory D, Johnston R, Pratt G, Watts M and Whatmore S 2009 Dictionary of Human Geography Wiley-Blackwell Chichester

Griffin G and Friedel M 1985 Discontinuous change in central Australia: some implications for of major ecological events for land management Journal of Arid Environments 9 63-80

Harrison C, Burgess J and Clark J 1998 Discounted knowledges: farmers' and residents understandings of nature conservation goals and policies Journal of Environmental Management 54 305-320

Hayes A 1999a CLMA: Where to from here? in CLMA ed Proceedings: CLMA Landcare Shindig - Towards Clean Green Beef, CLMA, Alice Springs No page numbers

Hayes J 1999b History of Centralian pastoralism in CLMA ed Proceedings: CLMA Landcare Shindig - Towards Clean Green Beef, CLMA, Alice Springs No page numbers

Haynes R 1998 Seeking the Centre: The Australian Desert in Literature, Art and Film Cambridge University Press Cambridge

Head L 1999 The northern myth revisited? Aborigines, environment and agriculture in the Ord River Irrigation Scheme Australian Geographer 30 141-158

Head L 2007 Cultural ecology: the problematic human and the terms of engagement Progress in Human Geography 31 837-846

Head L 2010 Cultural ecology: adaptation - retrofitting a concept? Progress in Human Geography 34 234-242

Heathcote R 1965 Back of Bourke: A Study in Land Appraisal and Settlement in Semi-arid Australia Cambridge University Press Melbourne

Heathcote R 1987 Images of a desert? Perceptions of arid Australia Australian Geographical Studies 25 3-25

Hinchliffe S 2008 Reconstituting nature conservation: Towards a careful political ecology Geoforum 39 88-97

Holmes J 2002 Diversity and change in Australia's rangelands: a post-productivist transition with a difference? Transactions of the Institute of British Geographers 27 362-384

Holmes J 2010 The Multifunctional Transition in Australia's Tropical Savannas: the Emergence of Consumption, Protection and Indigenous Values Geographical Research 48 265-280 
Holmes JH and Day P 1995 Identity, lifestyle and survival; value orientations of South Australian pastoralists The Rangeland Journal 17 193-212

Howitt R and Suchet-Pearson S 2006 Rethinking the building blocks: Ontological pluralism and the idea of 'management' Geografiska Annaler: Series B, Human Geography 88 323-335

Ingold T 2000 The Perception of the Environment: Essays in Livelihood, Dwelling, and Skill Routledge London

Ingold T 2005 Epilogue: Towards a politics of dwellling Conservation and Society 3 501508

Jepson P, Barua M, Ladle R and Buckingham K 2011 Towards an intradisciplinary biogeography: a response to Lorimer's 'lively biogeographies' of Asian elephant conservation Transactions of the Institute of British Geographers 36 170-174

Jones $\mathbf{O}$ and Cloke P 2002 Tree Cultures: The Place of Trees and Trees in their Place Berg Oxford

Knapp CN and Fernandez-Gimenez ME 2009 Understanding Change: Integrating Rancher Knowledge Into State-and-Transition Models Rangeland Ecology \& Management 62 510-521

Lane M, Robinson C and Taylor B 2009 Contested country : local and regional natural resources management in Australia CSIRO Publishing Collingwood, Vic.

Lawrence G, Richards C and Cheshire L 2004 The environmental enigma: Why do producers professing stewardship continue to practice poor natural resource management? Journal of Environmental Policy and Planning 6 251-270

Leff E 1985 Ethnobotany and anthropology as tools for a cultural conservation strategy in McNeely JA and Pitt D eds Culture and conservation: the human dimensions of environmental planning, Croom Helm, London 259-268

Letnic M 2000 Dispossession, degradation and extinction: environmental history in arid Australia Biodiversity and Conservation 9 295-308

Ling E 2010 Blame and Martyrs: The Commonwealth Government's Administration of the Northern Territory's Pastoral Industry, 1911-1978 Unpublished PhD Thesis Charles Darwin University Darwin

Lorimer J 2010 Elephants as companion species: the lively biogeographies of Asian elephant conservation in Sri Lanka Transactions of the Institute of British Geographers 35 491-506

Lunney D 2001 Causes of the extinction of native mammals of the Western Division of New South Wales: an ecological interpretation of the nineteenth century historical record The Rangeland Journal 23 44-70

MacLean K 2009 Re-conceptualising desert landscapes: unpacking historical narratives and contemporary realities for sustainable livelihood development in central Australia Geojournal 74 451-463

Meinig D 1988 On the Margins of the Good Earth South Australian Government Printer Adelaide

Morton S, Stafford-Smith D, Friedel M, Griffin G and Pickup G 1995 The stewardship of arid Australia: ecology and landscape management Journal of Environmental Management 43 195-218

Northern Territory Land Board 1964 Report by the Northern Territory Land Board on the Centralian Pastoral Industry Under Drought Conditions Northern Territory Land Board Darwin

Nygren S and Rikoon S 2009 Political Ecology Revisited: Integration of Politics and Ecology Does Matter Society \& Natural Resources 21 767-782 
Pannell D, Marshall G, Barr N, Curtis A, Vanclay F and Wilkinson R 2006 Understanding and Promoting adoption of Conservation technologies by Rural Landholders Australian Journal of Experimental Agriculture 46 1407-1424

Patton M 2002 Qualitative Research and Evaluation Methods Sage Newbury Park

Powell J 1977 Mirrors of the New World: Images and Image-Makers in the Settlement Process Dawson and Archon Books Folkestone and Hamden

Ratcliffe F 1947 Flying Fox and Drifting Sand: the Adventures of a Biologist in Australia Angus and Robertson Sydney

Richards C and Lawrence G 2008 Adaptation and change in Queensland's rangelands: Cell grazing as an emerging ideology of pastoral-ecology Land Use Policy 26 630-639

Robinson J 1999 Bushman of the Red Heart: Ben Nicker 1908-1941 Central Queensland University Press Rockhampton

Rose D 2004 Reports from a Wild Country: Ethics for Decolonisation University of NSW Press Sydney

Sayre NF 2004 Viewpoint: The need for qualitative research to understand ranch management Rangeland Ecology \& Management 57 668-674

Tonts M, Yarwood R and Jones R 2010 Global geographies of innovation diffusion: the case of the Australian cattle industry Geographical Journal 176 90-104

Vanclay F 2004 Social principles for agricultural extension to assist in the promotion of natural resource management Journal of Experimental Agriculture 44 213-222

Westoby M, Walker B and Noy-Meir I 1989 Rangeland management on the basis of model which does not seek to establish equilibrium Journal of Arid Environments 17 235239

Whatmore S 2002 Hybrid Geographies Sage London

Whatmore S 2006 Materialist returns: practising cultural geography in and for a more-thanhuman world Cultural Geographies 13 600-609

Woods M 2007 Engaging the global countryside: globalization, hybridity and the reconstitution of rural place Progress in Human Geography 31 485-507

Worrell R and Appleby M 2000 Stewardship of Natural Resources: Definition, Ethical and Practical Aspects Journal of Agricultural and Environmental Ethics 12 263-277 


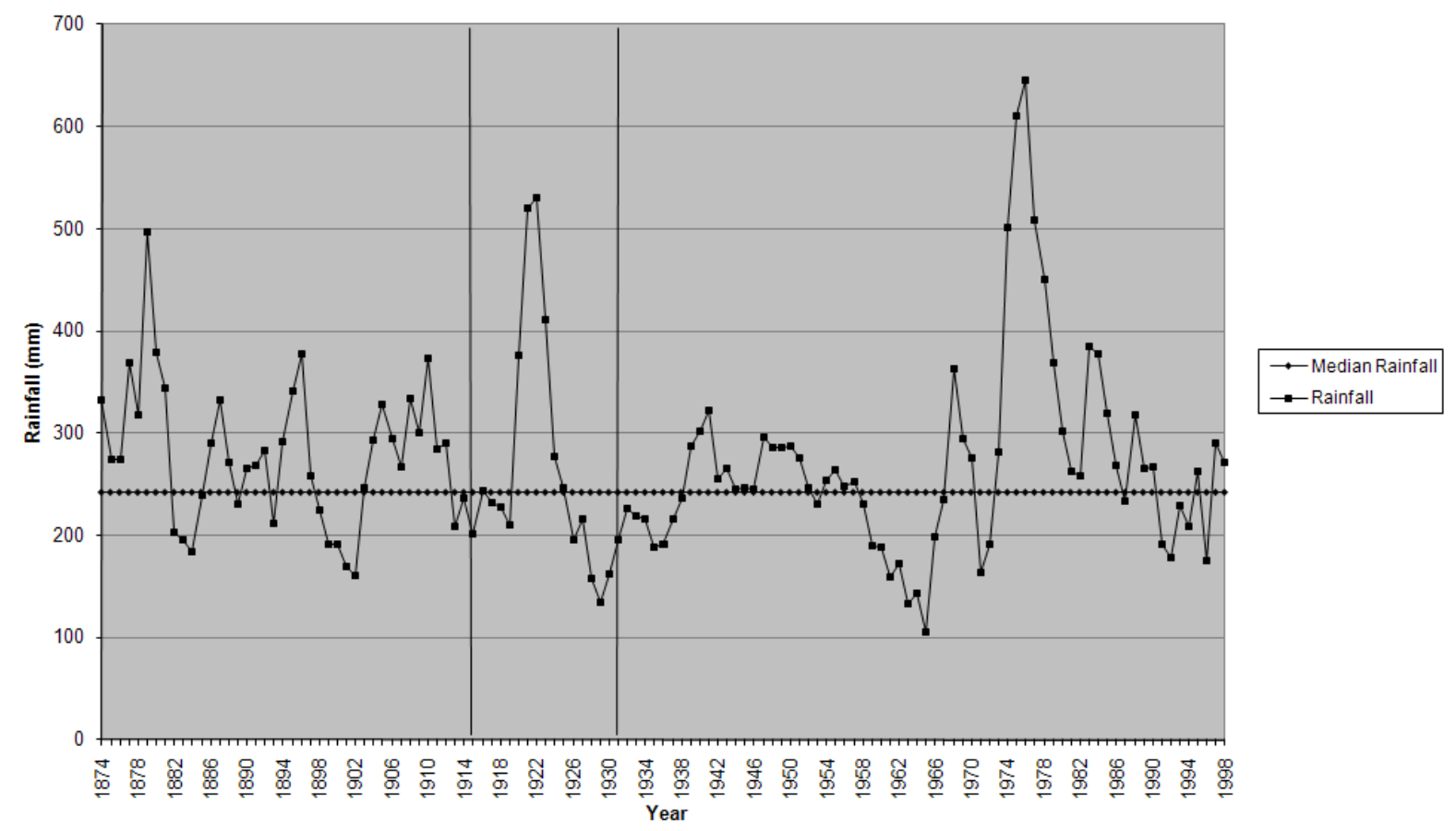

Figure One: Rainfall at Alice Springs ${ }^{5}$ 1874-1998 and the Nicker Family period at Glen Maggie 1914-1930

Source: Clewett (1999) Robinson, (1999). 